\title{
UTILIZAÇÃO DO CUSTO ANUAL UNIFORME EQUIVALENTE NA SUBSTITUIÇÃO DE FROTA EM EMPRESAS DE TRANSPORTE DE PASSAGEIROS
}

\author{
Ivan Henrique Vey ${ }^{1}$ \\ Robson Machado da Rosa ${ }^{2}$
}

\section{INTRODUÇÃO}

No mundo contemporâneo, em que as relações de comércio são dinâmicas e as mudanças inevitáveis, é necessário que as empresas estejam preparadas para enfrentar um mercado globalizado, cuja competitividade é acirrada, fazendo com que somente as empresas bem estruturadas sobrevivam na atmosfera de livre competição.

No caso das empresas de transporte coletivo urbano não é diferente. Elas também sofrem as influências da globalização, visto que não só a competitividade aumentou, mas, também, os consumidores passaram a exigir maior qualidade nos serviços prestados, o que só pode ser alcançado por empresas capacitadas.

Para que as empresas de transporte coletivo urbano satisfaçam as necessidades de seus clientes, é imprescindível que elas administrem seus recursos, principalmente os seus ativos permanentes, ou seja, suas frotas, com o maior cuidado possível, pois, caso não o façam, a qualidade de seus serviços será altamente prejudicada, fazendo com que elas não sejam bem vistas pela sociedade.

Entretanto, não basta às empresas suprirem as necessidades do mercado consumidor, elas também devem trazer retorno aos seus investidores, sócios ou acionistas, visto que os mesmos estão interessados nos resultados de seus empreendimentos.

Deste modo, desenvolveu-se o presente trabalho como forma de suprir as necessidades das empresas no que diz respeito ao cálculo da vida útil econômica dos ônibus que compõem as suas frotas. Seu objetivo principal foi o de propor uma ferramenta de análise de permutação de ativos fixos que auxilie a empresa na tomada de decisão, utilizando o método do custo anual uniforme equivalente (CAUE), que

\footnotetext{
1 Contador, Mestre em administração de empresas pela UFSC, Professor do Curso de Ciências Contábeis da UFSM e Vice-chefe do Departamento de Ciências Contábeis da UFSM. vey@ccsh.ufsm.br

${ }^{2}$ Contador, Professor do Curso de Ciências Contábeis UFSM e Sócio da empresa Esco Contabilidade e Assessoria. robson.esco@brturbo.com
} 
determinará o momento ótimo de substituição dos ônibus da frota, ou seja, calculará a vida útil econômica dos mesmos.

Para atingir tal objetivo partiu-se de um estudo de caso desenvolvido na empresa Alfa (nome fictício), que realiza transporte coletivo urbano na cidade de Santa Maria-RS. Aplicou-se o método do custo anual uniforme equivalente (CAUE) para determinar a vida útil econômica dos ônibus 133, 134 e 138, que compõem a linha n. ${ }^{\circ}$ 0168 da cidade. Sendo que foram coletados e interpretados os dados peculiares aos ônibus desde o ano de 1996, data das aquisições, até o ano de 2001.

\section{EMBASAMENTO TEÓRICO}

\subsection{Vida útil e vida útil econômica}

Uma das questões mais importantes para determinar o momento ideal da substituição de ativos depreciáveis, antes de tudo, é saber qual o período de vida útil e vida útil econômica que os mesmos possuem, pois na hora de aplicar o método de análise de substituição é preciso saber o período de vida útil do bem, visto que ele irá influenciar outro fator de extrema importância que é a depreciação.

Vida útil refere-se ao tempo máximo de utilização de um bem, estando relacionado com o esgotamento da capacidade produtiva do mesmo, não importando se ele está contribuindo positiva ou negativamente para formação do redito. Neste caso, a substituição do bem dar-se-á somente pela incapacidade dele realizar a atividade a que se destina.

Já a vida útil econômica envolve a estrutura econômico-financeira da empresa, e está relacionado com a eficiência e a produtividade do bem. Neste caso, a substituição dar-se-á pelo ponto em que o bem prestou o melhor serviço à empresa. Ou seja, deve ser conceituada como o período durante o qual o usuário pode considerar o bem como útil e proveitoso às suas atividades, não significando, contudo sua provável duração física.

\subsection{Investimento em ativos fixos}

As empresas investem com o objetivo de incrementar seus resultados, ou em último caso, manter o nível dos mesmos. A aplicação de recursos em ativos fixos é um investimento que servirá para a geração de rendas, contribuindo assim com a formação do rédito. 
São várias as razões que levam uma empresa a substituir um ativo fixo ou apenas baixa-lo, ou melhor, desativá-lo, entretanto, elas podem ser sintetizadas em três grupos que são:

a) Deterioração: que é causada pelo grau de utilização do equipamento, que no caso deste trabalho são ônibus, pela qualidade da manutenção e pela ação do tempo. Sendo que a deterioração provoca aumento dos custos operacionais, de manutenções e aumento da ociosidade do bem.

b) Avanço tecnológico: através dos avanços tecnológicos surgem equipamentos mais modernos e que trazem uma vantagem operacional à empresa, através de menores custos, maior grau de produção, agilidade e qualidade, fazendo com que o equipamento em uso torne-se desvantajoso ou obsoleto, comparando-o com os novos modelos disponíveis no mercado.

c) Inadequação: muitas empresas em busca de maior competitividade no mercado alteram suas linhas de produção ou apenas deixam de fabricar determinados produtos, por eles não serem mais lucrativos. Isso faz com que alguns equipamentos utilizados anteriormente, passem a ser dispensáveis à empresa por sua inadequação na nova linha de produção.

Sendo que para Ehrlich (1977, p. 82) os custos que influenciam a decisão de continuar ou não operando com o equipamento existente são:

a) custos de operação e manutenção, que são crescentes com o tempo;

b) custos de obsolescência, que provocam uma desvantagem relativa por não usar equipamento tecnologicamente mais moderno. Isto pode afetar a qualidade do produto;

c) custos de inadequação, que nos impedem de empregar um equipamento mais bem dimensionado (quanto a capacidade de produção) para as novas condições de mercado.

De Rocchi (1987, p. 13), em seus estudos destaca as variáveis fundamentais que devem ser estudadas em cada tipo de problema como pode-se observar na figura

FIGURA 1 - Variantes fundamentais no estudo das categorias de investimentos em ativos permanentes depreciáveis. 


\begin{tabular}{|c|c|c|}
\hline \multicolumn{2}{|r|}{ CLASSES DE PROJETOS } & Principais características e possíveis variantes \\
\hline \multirow{3}{*}{ 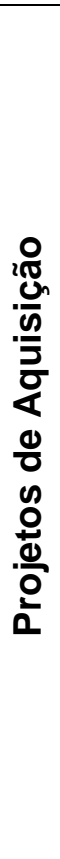 } & Caso Geral & $\begin{array}{l}\text { Em se tratando de casos em que existe uma única } \\
\text { alternativa para o investimento, o problema se } \\
\text { resume em analisar a conveniência ou não de } \\
\text { realizar o projeto. }\end{array}$ \\
\hline & $\begin{array}{l}\text { Projetos sem fins lucrativos } \\
\text { Projetos com rédito não } \\
\text { mensurável }\end{array}$ & $\begin{array}{l}\text { Quando estão disponíveis duas ou mais opções, a } \\
\text { principal preocupação será determinar qual delas } \\
\text { conduzirá a menores custos, ou qual delas oferece o } \\
\text { menor prazo de recuperação dos investimentos. }\end{array}$ \\
\hline & Projetos com fins lucrativos & $\begin{array}{l}\text { Estando disponíveis duas ou mais opções, busca-se } \\
\text { aquela que oferece o maior rédito total (acumulado } \\
\text { durante toda a vida útil econômica). Em igualdade de } \\
\text { condições quanto ao rédito total, opta-se pela de } \\
\text { menor prazo de recuperação. }\end{array}$ \\
\hline \multirow[t]{2}{*}{ 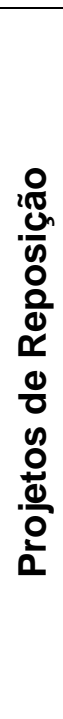 } & Projetos com fins lucrativos & $\begin{array}{l}\text { Em qualquer caso, o cerne do problema reside em } \\
\text { determinar o momento ideal (idade ótima) para } \\
\text { proceder à substituição. Isto significa determinar a } \\
\text { idade na qual a troca da máquina ou equipamento } \\
\text { propiciará a otimização dos investimentos, a } \\
\text { maximização dos réditos totais (acumulados durante } \\
\text { toda a vida útil econômica) e/ou os retornos sobre os } \\
\text { investimentos. }\end{array}$ \\
\hline & Outros casos & $\begin{array}{l}\text { Busca-se determinar a idade em que se conseguirá a } \\
\text { otimização dos Custos Totais, acumulados durante } \\
\text { toda a vida econômica do bem. }\end{array}$ \\
\hline & Projetos de Expansão & $\begin{array}{l}\text { Problemas e soluções semelhantes aos encontrados } \\
\text { nos projetos de aquisição inicial. }\end{array}$ \\
\hline & Projetos de Retratação & $\begin{array}{l}\text { A principal preocupação é identificar quais as } \\
\text { máquinas e equipamentos que, se forem } \\
\text { desativados, conduzirão à minimização do prejuízo } \\
\text { e/ou menor redução nos lucros futuros. }\end{array}$ \\
\hline
\end{tabular}

Fonte: De Rocchi (1987, p. 13)

Os problemas de substituição de ativos fixos podem ser agrupados segundo Casarotto Filho \& Kopittke (2000, p. 167) em cinco modelos tradicionais que são: a baixa sem reposição, substituição idêntica, substituição não idêntica, substituição com progresso tecnológico e substituição estratégica. 
No caso de substituição idêntica, o mais importante é determinar a vida útil econômica do bem em análise, para assim chegar ao momento ótimo de substituição, sendo que para resolver este problema deve-se ter em mãos informações sobre os custos de investimento, manutenção e reparação. Não sendo relevante obter informações referentes às receitas geradas pelo bem, pois, teoricamente, elas serão mantidas, visto que o bem novo será idêntico ao antigo.

Assim, Casarotto Filho \& Kopittke (2000, p. 170) dizem que: "a determinação da vida econômica consiste em achar os custos ou resultados anuais uniformes equivalentes (CAUE ou VAUE) do ativo para todas as vidas úteis possíveis. O ano para o qual o CAUE é mínimo ou o VAUE é máximo é o da vida econômica do ativo". Como pode ser visto no gráfico a seguir:

FIGURA 2 - Representação gráfica do custo anual uniforme equivalente.

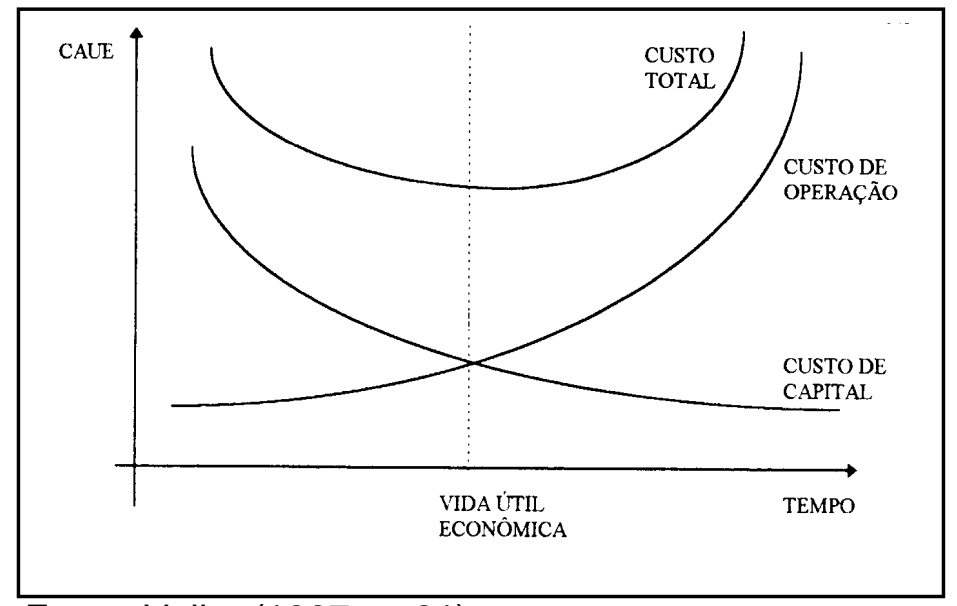

Fonte: Velho (1997, p. 21)

\subsection{Métodos de avaliação de investimentos}

Segundo Ehrlich (1977, p. 14): "Antes de desenvolver a estrutura matemática necessária para a avaliação das propostas de aplicação do capital, é conveniente postular alguns princípios qualitativos que fundamentam a racionalização das decisões."

Para determinar o momento ideal de substituição de ativos depreciáveis ou analisar alternativas de investimentos, existem vários métodos disponíveis para auxiliar a tomada de decisão. Entretanto, logo a seguir é dado destaque apenas aos métodos principais, sendo que eles serão divididos em três classes, baseadas nas classificações de Dorneles (2001) e De Rocchi (1987). Assim, neste estudo, os métodos foram classificados nas seguintes classes: 
1) Métodos que utilizam fluxos de caixa em termos nominais:

- Pay-back nominal;

- Taxa de retorno contábil ou taxa média de retorno.

2) Métodos que utilizam fluxos de caixa reais:

- Valor presente líquido (VPL);

- Valor anual uniforme equivalente (VAUE);

- Custo anual uniforme equivalente (CAUE);

- Taxa interna de retorno (TIR);

- Índice de lucratividade (IL);

- Pay-Back atualizado ou descontado.

3) Métodos da pesquisa operacional:

- Método MAPI ou Terborgh;

- Método de Orenstein;

- Método de Clapham.

Após vários estudos realizados sobre os métodos acima citados, optou-se pela utilização do método do custo anual uniforme equivalente (CAUE), o qual é descrito na seqüência do trabalho.

\subsection{Método do custo anual uniforme equivalente}

O método do custo anual uniforme equivalente (CAUE) é semelhante ao do valor anual uniforme equivalente, porém o primeiro faz uma comparação entre os custos dos projetos de investimentos, ao passo que o segundo compara todos os componentes do fluxo de caixa das alternativas.

Ao transformar todos os custos do bem para custos anuais equivalentes, com a aplicação de uma determinada taxa de juro correspondente ao custo de capital sobre o investimento ou a taxa mínima atrativa, tem-se por objetivo determinar em que ano ocorre o menor custo anual equivalente, determinando assim, o período ideal de substituição do ativo depreciável ou seja, a sua vida útil econômica.

Segundo De Rocchi (1987, p. 18) "para se calcularem os custos anuais equivalentes, utiliza-se o FATOR DE RECUPERAÇÃO DO CAPITAL, que é uma função financeira tabelada, e que pode ser calculada, e é representada pela equação e símbolos abaixo":

$$
\frac{1}{a n]}=\frac{i(1+i)^{n}}{(1+i)^{n}-1}
$$

O mesmo autor (1987, p. 19) diz que através de tal método pode-se: 
a) comparar duas ou mais oportunidades de investimento; pelo método do Custo Anual, a alternativa que apresentar o mais baixo custo anual, ajustado ao fator tempo, será a mais conveniente para a empresa;

b) determinar o momento ideal para a substituição de uma máquina ou equipamento; o processo de análise está baseado na premissa de que, quanto mais longa for a vida de um Ativo Depreciável, tanto mais baixo se tornará o Custo Médio Anual do Capital, pois o desembolso se distribuirá sobre um período mais longo de tempo; isso, entretanto, será contrabalançado por custos operacionais crescentes; e, assim sendo, a vida útil econômica se encerra no período (ano) em que o custo total, devidamente ajustado ao tempo, atingir um mínimo.

Entretanto, para utilizar o método do custo anual uniforme equivalente, necessário se faz obter algumas informações sobre o bem que estará sob análise, tais como:

- valor do investimento ou de aquisição;

- valor de revenda ou valor residual ao final de cada ano da vida útil do bem;

- os custos operacionais;

- o custo de capital ou a taxa mínima atrativa.

Neste momento começam a aparecer algumas limitações do método, visto que alguns dos dados necessários para colocá-lo em prática nem sempre estão disponíveis e muitas vezes são de difícil obtenção, seja pela empresa não manter uma base de dados históricos confiável referente ao bem em análise, ou simplesmente pela grande dificuldade de obtenção de algumas informações externas, que não dependem do controle da empresa.

O valor do investimento é uma informação que, normalmente, é de fácil obtenção, pois quando a empresa está analisando a viabilidade da aplicação de capital em um determinado bem, ela saberá o valor que custa o mesmo. Todavia, quando se tratar de determinar a vida útil econômica de um ativo fixo que já integra o ativo imobilizado da empresa, poderá surgir alguma dificuldade caso a empresa não possua uma escrituração contábil regular e bem estruturada, visto que desta forma os dados referentes à aquisição não estarão disponíveis.

Uma das problemáticas do método está ligada a obtenção do valor residual, ao final de cada ano da vida útil do bem já pertencente à empresa, ou ao final de cada período do projeto em questão. No primeiro caso, a solução pode ser obtida através 
da pesquisa, junto ao mercado especializado, do valor de mercado do bem em questão. Já no segundo caso, pode-se recorrer a consulta de manuais técnicos, revistas especializadas, entre outros, onde conste as curvas padrões das depreciações previstas para cada tipo de bem. Apesar de parecer de fácil solução, este problema é extremamente difícil, pois a empresa depende muito da existência de entidades ou órgãos que disponibilizem estes tipos de informações.

Quanto aos custos operacionais, poderá surgir alguma problemática quando se tratar de avaliação da viabilidade de projetos de investimento, visto que os custos, para cada período dos projetos, deverão ser estimados, o que pode levar a empresa a tomar decisões errôneas, pelo fato de basear-se em previsões que podem não se concretizar.

O último fator que deve ser considerado é a determinação do custo de capital ou da taxa mínima de atratividade, que será utilizada para transformar os valores do fluxo de caixa em anualidades. Este problema pode ser resolvido calculando-se o custo de capital ponderado da empresa ou determinando uma taxa mínima atrativa, que segundo Puccini, Marques, Hess \& Paes (1969, p. 39) "deve render, no mínimo, a taxa de juros equivalente à rentabilidade das aplicações correntes e de pouco risco".

Como este trabalho trata da determinação da vida útil econômica de bens que podem ser substituídos por outros semelhantes, não alterando o valor das receitas auferidas, este método encaixa-se perfeitamente para solucionar o problema da determinação do momento ideal ou ótimo de substituição, visto considerar apenas os custos operacionais, que geralmente crescem com o tempo, e o custo de capital, que decresce com o passar dos anos.

Sendo que para aplicação prática do método pode-se recorrer a planilhas eletrônicas Excel ${ }^{\circledR}$.

\section{APLICAÇÃO DO CUSTO ANUAL UNIFORME EQUIVALENTE}

Para determinar o momento ótimo de substituição dos ônibus em análise neste trabalho, foi utilizado o método do custo anual uniforme equivalente pelo fato dele poder ser operacionalizado utilizando-se apenas informações referentes aos custos dos bens, não necessitando obter informações sobre as receitas, e também por ele ser indicado, por alguns dos autores consultados para desenvolver este trabalho, para determinar a vida útil econômica de bens que possam ser substituídos por outros iguais ou semelhantes.

Como já foi dito anteriormente, os ônibus de números 133, 134 e 138, ambos com chassis Mercedes-Benz OF 1318, carrocerias Svelto-Comil, fabricados no ano de 
1996, que fazem parte da linha interurbana 0168, são os bens que estiveram sob análise neste trabalho, sendo estudados individualmente, ou seja, foi calculada a vida útil econômica de cada um deles separadamente, pois assim, não se corre o risco de permitir que o desempenho de um influencie nos resultados dos demais e vice-versa.

Para colocar em prática este método, como já foi dito, é necessário possuir informações sobre os valores dos investimentos ou os preços de aquisições, os valores de revenda ou residuais ao final de cada ano da vida útil dos bens, os custos operacionais dos mesmos e o custo de capital ou a taxa mínima atrativa da empresa.

Também é importante salientar que os ônibus percorreram, em média, a mesma quilometragem de um ano para outro, então, conclui-se que as variações dos custos foram influenciadas exclusivamente pelo desgaste dos bens com o passar dos anos e pela perícia na utilização deles.

Pretendendo atender aos objetivos do trabalho, buscou-se coletar junto à empresa informações que suprissem as necessidades para desenvolver o método do custo anual uniforme equivalente, utilizado como ferramenta para determinar a vida útil econômica dos bens, ou seja, o momento ótimo de substituição dos ônibus. Assim, a seguir serão apresentados os dados coletados para operacionalizar o método.

\subsection{Valor do investimento}

O valor do investimento ou da aquisição de cada bem, em análise no presente estudo, foi obtido através da pesquisa nos controles patrimoniais da empresa, onde constam individualmente as informações sobre a data e valor de aquisição de todos os ônibus da empresa, sendo que os valores encontrados para os ônibus 133, 134 e 138 foram, respectivamente, $\mathrm{R} \$ 66.201,99, \mathrm{R} \$ 67.300,46$ e $\mathrm{R} \$ 69.800,14$. No controle patrimonial, além das informações já citadas, também constam dados sobre a ocorrência de eventuais imobilizações que aumentaram os valores patrimoniais dos bens.

No caso dos ônibus em estudo, verificou-se que todos sofreram aumentos patrimoniais oriundos de imobilizações realizadas após suas aquisições, sendo que no QUADRO 1, será demonstrado em que anos e que valores foram acrescentados aos valores originais dos investimentos.

QUADRO 1 - Valores das imobilizações (R\$).

\begin{tabular}{|c|c|c|c|}
\hline \multirow{2}{*}{ Anos } & \multicolumn{3}{|c|}{ N..$^{\circ}$ dos ônibus } \\
\cline { 2 - 4 } & 133 & 134 & 138 \\
\hline 1996 & - & $3.478,02$ & - \\
\hline 1997 & - & - & - \\
\hline
\end{tabular}




\begin{tabular}{|c|c|c|c|}
\hline $\mathbf{1 9 9 8}$ & $1.659,71$ & - & - \\
\hline $\mathbf{1 9 9 9}$ & 600,00 & - & - \\
\hline $\mathbf{2 0 0 0}$ & $3.191,06$ & $2.484,33$ & $2.697,74$ \\
\hline $\mathbf{2 0 0 1}$ & - & - & - \\
\hline
\end{tabular}

Para determinar os valores totais dos investimentos, que foram utilizados para calcular a vida útil econômica de cada ônibus, além dos valores de aquisições, devese somar as imobilizações ocorridas em cada bem, mas é importante que tais valores sejam trazidos para o início do ano de 1996, ou seja, para o mesmo período das aquisições, utilizando-se a taxa mínima atrativa que será determinada mais adiante.

Desta forma, somando-se os valores originais das aquisições dos bens com suas imobilizações posteriores, chegou-se aos seguintes valores totais dos investimentos: $\mathrm{R} \$ 69.546,49$ para o ônibus $133, \mathrm{R} \$ 71.794,76$ para o ônibus 134 e $\mathrm{R} \$$ 71.315,29 para o ônibus 138 .

\subsection{Valores residuais ou de revenda}

Para determinar os valores residuais dos ônibus, recorreu-se ao cálculo da depreciação exponencial como forma de calcular-se as perdas de valores dos bens durante os anos, considerando-se que os bens possuam no máximo 10 anos de vida útil, visto que a empresa possui alguns ônibus com 10 ou mais anos de utilização, alcançando um valor residual de $\mathrm{R} \$ 9.000,00$ ao final do período de vida útil, valor este baseado nos últimos quatro ônibus vendidos pela empresa, no ano de 2001, cujos anos de fabricação eram 1988, 1989 e 1990, e que foram vendidos por valores entre $\mathrm{R} \$ 8.000,00$ e $\mathrm{R} \$ 9.000,00$.

Os valores residuais, antes do cálculo do imposto de renda sobre o ganho de capital, dos ônibus 133, 134 e 138, estão demonstrados respectivamente nos QUADROS 2, 3 e 4.

QUADRO 2 - Valores residuais (R\$) do ônibus 133, antes do imposto de renda.

\begin{tabular}{|c|c|c|c|}
\hline Anos & $\begin{array}{c}\text { Depreciação } \\
\text { Anual }\end{array}$ & $\begin{array}{c}\text { Depreciação } \\
\text { Acumulada }\end{array}$ & $\begin{array}{c}\text { Valor } \\
\text { Residual }\end{array}$ \\
\hline 1996 & $12.860,99$ & $12.860,99$ & $56.685,50$ \\
\hline 1997 & $10.482,65$ & $23.343,65$ & $46.202,84$ \\
\hline 1998 & $8.544,13$ & $31.887,78$ & $37.658,71$ \\
\hline 1999 & $6.964,10$ & $38.851,88$ & $30.694,61$ \\
\hline 2000 & $5.676,25$ & $44.528,13$ & $25.018,36$ \\
\hline 2001 & $4.626,56$ & $49.154,69$ & $20.391,80$ \\
\hline
\end{tabular}




\begin{tabular}{|c|c|c|c|}
\hline 2002 & $3.770,99$ & $52.925,67$ & $16.620,82$ \\
\hline 2003 & $3.073,63$ & $55.999,30$ & $13.547,19$ \\
\hline 2004 & $2.505,23$ & $58.504,54$ & $11.041,95$ \\
\hline 2005 & $2.041,95$ & $60.546,49$ & $9.000,00$ \\
\hline
\end{tabular}

QUADRO 3 - Valores residuais (R\$) do ônibus 134, antes do imposto de renda.

\begin{tabular}{|c|c|c|c|}
\hline Anos & $\begin{array}{c}\text { Depreciação } \\
\text { Anual }\end{array}$ & $\begin{array}{c}\text { Depreciação } \\
\text { Acumulada }\end{array}$ & $\begin{array}{c}\text { Valor } \\
\text { Residual }\end{array}$ \\
\hline 1996 & $13.462,64$ & $13.462,64$ & $58.332,12$ \\
\hline 1997 & $10.938,19$ & $24.400,83$ & $47.393,93$ \\
\hline 1998 & $8.887,11$ & $33.287,94$ & $38.506,82$ \\
\hline 1999 & $7.220,63$ & $40.508,57$ & $31.286,19$ \\
\hline 2000 & $5.866,65$ & $46.375,22$ & $25.419,54$ \\
\hline 2001 & $4.766,56$ & $51.141,79$ & $20.652,97$ \\
\hline 2002 & $3.872,76$ & $55.014,54$ & $16.780,22$ \\
\hline 2003 & $3.146,55$ & $58.161,10$ & $13.633,66$ \\
\hline 2004 & $2.556,53$ & $60.717,62$ & $11.077,14$ \\
\hline 2005 & $2.077,14$ & $62.794,76$ & $9.000,00$ \\
\hline
\end{tabular}

QUADRO 4 - Valores residuais (R\$) do ônibus 138, antes do imposto de renda.

\begin{tabular}{|c|c|c|c|}
\hline Anos & $\begin{array}{c}\text { Depreciação } \\
\text { Anual }\end{array}$ & $\begin{array}{c}\text { Depreciação } \\
\text { Acumulada }\end{array}$ & $\begin{array}{c}\text { Valor } \\
\text { Residual }\end{array}$ \\
\hline 1996 & $13.333,90$ & $13.333,90$ & $57.981,39$ \\
\hline 1997 & $10.840,84$ & $24.174,74$ & $47.140,55$ \\
\hline 1998 & $8.813,92$ & $32.988,66$ & $38.326,63$ \\
\hline 1999 & $7.165,97$ & $40.154,63$ & $31.160,66$ \\
\hline 2000 & $5.826,14$ & $45.980,78$ & $25.334,51$ \\
\hline 2001 & $4.736,82$ & $50.717,60$ & $20.597,69$ \\
\hline 2002 & $3.851,17$ & $54.568,77$ & $16.746,52$ \\
\hline 2003 & $3.131,12$ & $57.699,89$ & $13.615,40$ \\
\hline 2004 & $2.545,69$ & $60.245,57$ & $11.069,72$ \\
\hline 2005 & $2.069,72$ & $62.315,29$ & $9.000,00$ \\
\hline
\end{tabular}

Entretanto, quando uma empresa vende um bem de seu ativo permanente, e o valor de revenda é maior do que o valor contábil do mesmo, ocorre um ganho de capital, que é tributado pelo imposto de renda com uma alíquota de 15\%,. O imposto deve ser subtraído do valor residual antes do imposto de renda, para desta forma chegar-se ao valor residual líquido ou após o imposto de renda. Assim, a seguir será 
demonstrado os valores residuais dos ônibus 133, 134 e 138, do ano de 1996 a 2001, depois do imposto de renda, respectivamente nos QUADROS 5, 6 e 7, sendo que os valores contábeis dos bens foram extraídos dos controles patrimoniais da empresa.

QUADRO 5 - Valores residuais (R\$) do ônibus 133, após a dedução do imposto de renda sobre o ganho de capital.

\begin{tabular}{|c|c|c|c|c|c|}
\hline Anos & $\begin{array}{c}\text { Valor } \\
\text { Contábil }\end{array}$ & $\begin{array}{c}\text { Valor } \\
\text { Residual } \\
\text { antes do IR }\end{array}$ & $\begin{array}{c}\text { Ganho de } \\
\text { Capital }\end{array}$ & $\begin{array}{c}\text { Imposto de } \\
\text { Renda }\end{array}$ & $\begin{array}{c}\text { Valor } \\
\text { Residual } \\
\text { após IR }\end{array}$ \\
\hline 1996 & $51.707,37$ & $56.685,50$ & $4.978,13$ & 746,72 & $55.938,78$ \\
\hline 1997 & $31.914,40$ & $46.202,84$ & $14.288,44$ & $2.143,27$ & $44.059,57$ \\
\hline 1998 & $17.739,71$ & $37.658,71$ & $19.919,00$ & $2.987,85$ & $34.670,86$ \\
\hline 1999 & $4.757,35$ & $30.694,61$ & $25.937,26$ & $3.890,59$ & $26.804,02$ \\
\hline 2000 & $3.190,86$ & $25.018,36$ & $21.827,50$ & $3.274,13$ & $21.744,24$ \\
\hline 2001 & $2.499,52$ & $20.391,80$ & $17.892,28$ & $2.683,84$ & $17.707,96$ \\
\hline
\end{tabular}

QUADRO 6 - Valores residuais (R\$) do ônibus 134, após a dedução do imposto de renda sobre o ganho de capital.

\begin{tabular}{|c|c|c|c|c|c|}
\hline Anos & $\begin{array}{c}\text { Valor } \\
\text { Contábil }\end{array}$ & $\begin{array}{c}\text { Valor } \\
\text { Residual } \\
\text { antes do IR }\end{array}$ & $\begin{array}{c}\text { Ganho de } \\
\text { Capital }\end{array}$ & $\begin{array}{c}\text { Imposto de } \\
\text { Renda }\end{array}$ & $\begin{array}{c}\text { Valor } \\
\text { Residual } \\
\text { após IR }\end{array}$ \\
\hline 1996 & $58.573,94$ & $58.332,12$ & $(241,82)$ & - & $58.332,12$ \\
\hline 1997 & $38.447,07$ & $47.393,93$ & $8.946,86$ & $1.342,03$ & $46.051,90$ \\
\hline 1998 & $22.345,55$ & $38.506,82$ & $16.161,27$ & $2.424,19$ & $36.082,63$ \\
\hline 1999 & $8.544,23$ & $31.286,19$ & $22.741,96$ & $3.411,29$ & $27.874,90$ \\
\hline 2000 & $4.049,23$ & $25.419,54$ & $21.370,31$ & $3.205,55$ & $22.213,99$ \\
\hline 2001 & $3.510,90$ & $20.652,97$ & $17.142,07$ & $2.571,31$ & $18.081,66$ \\
\hline
\end{tabular}

QUADRO 7 - Valores residuais (R\$) do ônibus 138, após a dedução do imposto de renda sobre o ganho de capital.

\begin{tabular}{|c|c|c|c|c|c|}
\hline Anos & $\begin{array}{c}\text { Valor } \\
\text { Contábil }\end{array}$ & $\begin{array}{c}\text { Valor } \\
\text { Residual } \\
\text { antes do IR }\end{array}$ & $\begin{array}{c}\text { Ganho de } \\
\text { Capital }\end{array}$ & $\begin{array}{c}\text { Imposto de } \\
\text { Renda }\end{array}$ & $\begin{array}{c}\text { Valor } \\
\text { Residual } \\
\text { após IR }\end{array}$ \\
\hline 1996 & $61.656,76$ & $57.981,39$ & $(3.675,37)$ & - & $57.981,39$ \\
\hline 1997 & $41.298,42$ & $47.140,55$ & $5.842,13$ & 876,32 & $46.264,23$ \\
\hline 1998 & $25.011,70$ & $38.326,63$ & $13.314,93$ & $1.997,24$ & $36.329,39$ \\
\hline
\end{tabular}




\begin{tabular}{|c|c|c|c|c|c|}
\hline 1999 & $11.051,62$ & $31.160,66$ & $20.109,04$ & $3.016,36$ & $28.144,30$ \\
\hline 2000 & $2.652,78$ & $25.334,51$ & $22.681,73$ & $3.402,26$ & $21.932,25$ \\
\hline 2001 & $2.068,30$ & $20.597,69$ & $18.529,39$ & $2.779,41$ & $17.818,28$ \\
\hline
\end{tabular}

\subsection{Custos operacionais}

Para estabelecer o valor total dos custos operacionais dos ônibus que estão sob análise, os mesmos foram classificados nos seguintes grupos:

a) Peças de reposição: que é composto por gastos com peças integrantes dos eixos, motor, freios, caixa, chassi, sistema de resfriamento, diferencial, eletricidade e funilaria.

b) Rodagem: que é composto por gastos com conserto de pneus, pneus recapados, pneus novos, câmaras, protetores, combustível, lubrificantes e aditivos.

c) Serviços de terceiros: que são compostos por gastos com mão-de-obra terceirizada e peças mecânicas.

d) Outros custos: que é composto por gastos com material de expediente.

e) Mão-de-obra da manutenção: que é composto pelos gastos com salários e encargos dos funcionários que trabalham no setor de manutenção da empresa.

QUADRO 8 - Custos operacionais totais (R\$) dos seguintes grupos de classificação: peças de reposição, rodagem, serviços de terceiros e outros custos.

\begin{tabular}{|c|c|c|c|}
\hline \multirow{2}{*}{ Anos } & \multicolumn{3}{|c|}{ N. $^{\mathbf{0}}$ dos ônibus } \\
\cline { 2 - 4 } & $\mathbf{1 3 3}$ & $\mathbf{1 3 4}$ & $\mathbf{1 3 8}$ \\
\hline $\mathbf{1 9 9 6}$ & $13.603,14$ & $12.259,51$ & $6.308,92$ \\
\hline $\mathbf{1 9 9 7}$ & $13.865,00$ & $15.090,47$ & $13.630,74$ \\
\hline $\mathbf{1 9 9 8}$ & $15.189,55$ & $17.687,10$ & $17.660,83$ \\
\hline $\mathbf{1 9 9 9}$ & $15.492,11$ & $21.462,33$ & $19.983,79$ \\
\hline $\mathbf{2 0 0 0}$ & $31.474,20$ & $25.502,63$ & $30.662,05$ \\
\hline $\mathbf{2 0 0 1}$ & $36.098,20$ & $31.598,28$ & $35.797,66$ \\
\hline
\end{tabular}

Como a empresa não possui informações sobre os custos da mão-de-obra da manutenção individualizada para cada ônibus, visto não ter um controle do tempo das manutenções, resolveu-se determinar uma chave de rateio para calcular o valor de tais custos.

A chave de rateio desenvolvida para resolver o problema, baseia-se na razão entre os valores dos custos operacionais anuais, demonstrados no QUADRO 8, e os 
valores dos custos totais operacionais anuais da empresa com peças de reposição, rodagem, serviços de terceiros e outros custos, que a seguir, nos QUADROS 9, 10 e 11, serão representados pela sigla "CTOA". A taxa percentual resultante deste cálculo foi aplicada sobre o valor total dos custos da mão-de-obra da manutenção da empresa, que são representados pela sigla "CTM" nos QUADROS 9, 10 e 11, chegando-se deste modo ao valor da mão-de-obra de cada ônibus em estudo.

Assim, chega-se aos valores dos custos da mão-de-obra da manutenção dos anos de 1996 ao 2001 de cada ônibus, sendo que os custos do ônibus 133 serão demonstrados nos QUADRO 9, os do ônibus 134 no QUADRO 10 e o do ônibus 138 no QUADRO 11.

QUADRO 9 - Custos da mão-de-obra da manutenção (R\$) referente ao ônibus 133.

\begin{tabular}{|c|c|c|c|c|c|}
\hline Anos & CTOA & $\begin{array}{c}\text { Custos } \\
\text { Operacionai } \\
\text { s (Quadro 1) }\end{array}$ & $\begin{array}{c}\text { Chave de } \\
\text { Rateio }\end{array}$ & $\begin{array}{c}\text { Custo da } \\
\text { mão-de-obra } \\
\text { da }\end{array}$ & $\begin{array}{c}\text { CTM } \\
\text { manutenção }\end{array}$ \\
\hline $\mathbf{1 9 9 6}$ & $1.674 .555,15$ & $13.603,14$ & $0,8123 \%$ & $285.782,69$ & $2.321,54$ \\
\hline $\mathbf{1 9 9 7}$ & $1.726 .538,10$ & $13.865,00$ & $0,8031 \%$ & $369.627,85$ & $2.968,30$ \\
\hline $\mathbf{1 9 9 8}$ & $1.772 .536,39$ & $15.189,55$ & $0,8569 \%$ & $372.792,91$ & $3.194,61$ \\
\hline $\mathbf{1 9 9 9}$ & $2.015 .803,63$ & $15.492,11$ & $0,7685 \%$ & $397.034,25$ & $3.051,34$ \\
\hline $\mathbf{2 0 0 0}$ & $2.580 .776,25$ & $31.474,20$ & $1,2196 \%$ & $418.076,60$ & $5.098,71$ \\
\hline $\mathbf{2 0 0 1}$ & $3.203 .595,27$ & $36.098,20$ & $1,1268 \%$ & $610.311,61$ & $6.877,01$ \\
\hline
\end{tabular}

QUADRO 10 - Custos da mão-de-obra da manutenção (R\$) referente ao ônibus 134.

\begin{tabular}{|c|c|c|c|c|c|}
\hline Anos & CTOA & $\begin{array}{c}\text { Custos } \\
\text { Operacionai } \\
\text { s(Quadro 1) }\end{array}$ & $\begin{array}{c}\text { Chave de } \\
\text { Rateio }\end{array}$ & $\begin{array}{c}\text { Custo da } \\
\text { mão-de-obra } \\
\text { da }\end{array}$ \\
\hline $\mathbf{1 9 9 6}$ & $1.674 .555,15$ & $12.259,51$ & $0,7321 \%$ & $285.782,69$ & $2.092,23$ \\
\hline $\mathbf{1 9 9 7}$ & $1.726 .538,10$ & $15.090,47$ & $0,8740 \%$ & $369.627,85$ & $3.230,66$ \\
\hline $\mathbf{1 9 9 8}$ & $1.772 .536,39$ & $17.687,10$ & $0,9978 \%$ & $372.792,91$ & $3.719,88$ \\
\hline $\mathbf{1 9 9 9}$ & $2.015 .803,63$ & $21.462,33$ & $1,0647 \%$ & $397.034,25$ & $4.227,24$ \\
\hline $\mathbf{2 0 0 0}$ & $2.580 .776,25$ & $25.502,63$ & $0,9882 \%$ & $418.076,60$ & $4.131,34$ \\
\hline $\mathbf{2 0 0 1}$ & $3.203 .595,27$ & $31.598,28$ & $0,9863 \%$ & $610.311,61$ & $6.019,74$ \\
\hline
\end{tabular}

QUADRO 11 - Custos da mão-de-obra da manutenção (R\$) referente ao ônibus 138. 


\begin{tabular}{|c|c|c|c|c|c|}
\hline Anos & CTOA & $\begin{array}{c}\text { Custos } \\
\text { Operacionai } \\
\text { s (Quadro 1) }\end{array}$ & $\begin{array}{c}\text { Chave de } \\
\text { Rateio }\end{array}$ & CTM & $\begin{array}{c}\text { Custo da } \\
\text { mão-de-obra } \\
\text { da } \\
\text { manutenção }\end{array}$ \\
\hline $\mathbf{1 9 9 6}$ & $1.674 .555,15$ & $6.308,92$ & $0,3768 \%$ & $285.782,69$ & $1.076,69$ \\
\hline $\mathbf{1 9 9 7}$ & $1.726 .538,10$ & $13.630,74$ & $0,7895 \%$ & $369.627,85$ & $2.918,15$ \\
\hline $\mathbf{1 9 9 8}$ & $1.772 .536,39$ & $17.660,83$ & $0,9964 \%$ & $372.792,91$ & $3.714,36$ \\
\hline $\mathbf{1 9 9 9}$ & $2.015 .803,63$ & $19.983,79$ & $0,9914 \%$ & $397.034,25$ & $3.936,02$ \\
\hline $\mathbf{2 0 0 0}$ & $2.580 .776,25$ & $30.662,05$ & $1,1881 \%$ & $418.076,60$ & $4.967,14$ \\
\hline $\mathbf{2 0 0 1}$ & $3.203 .595,27$ & $35.797,66$ & $1,1174 \%$ & $610.311,61$ & $6.819,75$ \\
\hline
\end{tabular}

Após o cálculo dos custos da mão-de-obra da manutenção, ainda tem-se que somar os valores do IPVA, seguro obrigatório e licenciamentos dos ônibus, extraídos dos balancetes de verificação da empresa, onde foram encontrados os valores destacados no QUADRO 12.

QUADRO 12 - Valores (R\$) do IPVA, seguro obrigatório e licenciamento.

\begin{tabular}{|c|c|c|c|}
\hline \multirow{2}{*}{ Anos } & \multicolumn{3}{|c|}{ N. $^{\circ}$ dos ônibus } \\
\cline { 2 - 4 } & $\mathbf{1 3 3}$ & $\mathbf{1 3 4}$ & $\mathbf{1 3 8}$ \\
\hline $\mathbf{1 9 9 6}$ & 357,99 & 357,99 & 357,99 \\
\hline $\mathbf{1 9 9 7}$ & 305,20 & 305,20 & 305,20 \\
\hline $\mathbf{1 9 9 8}$ & 305,80 & 305,80 & 305,80 \\
\hline $\mathbf{1 9 9 9}$ & 320,79 & 320,79 & 320,79 \\
\hline $\mathbf{2 0 0 0}$ & 411,23 & 388,35 & 411,23 \\
\hline $\mathbf{2 0 0 1}$ & 374,39 & 371,19 & 371,19 \\
\hline
\end{tabular}

Somando-se os valores do QUADRO 8, com os custos da mão-de-obra da manutenção, encontrados para os ônibus 133, 134 e 138, respectivamente nos QUADROS 9, 10 e 11, chega-se aos valores demonstrados no QUADRO 13, que representam o total dos custos operacionais sem considerar os valores do QUADRO 12.

QUADRO 13 - Custos operacionais totais (R\$), sem considerar os valores do IPVA, seguro obrigatório e licenciamento.

\begin{tabular}{|c|c|c|c|c|c|c|c|c|c|}
\hline \multirow{2}{*}{$\begin{array}{c}\text { Ano } \\
\text { s }\end{array}$} & \multicolumn{3}{|c|}{ Custos Operacionais (Quadro } & \multicolumn{2}{|c|}{$\begin{array}{c}\text { Custos da Mão-de-Obra da } \\
\text { Manutenção }\end{array}$} & \multicolumn{3}{c|}{ Custos Operacionais Totais } \\
\cline { 2 - 10 } & $\mathbf{1 3 3}$ & $\mathbf{1 3 4}$ & $\mathbf{1 3 8}$ & $\mathbf{1 3 3}$ & $\mathbf{1 3 4}$ & $\mathbf{1 3 8}$ & $\mathbf{1 3 3}$ & $\mathbf{1 3 4}$ & $\mathbf{1 3 8}$ \\
\hline $\mathbf{1 9 9 6}$ & $13.603,14$ & $12.259,51$ & $6.308,92$ & $2.321,54$ & $2.092,23$ & $1.076,69$ & $15.924,68$ & $14.351,74$ & $7.385,61$ \\
\hline
\end{tabular}




\begin{tabular}{|l|l|l|l|l|l|l|l|l|l|}
\hline 1997 & $13.865,00$ & $15.090,47$ & $13.630,74$ & $2.968,30$ & $3.230,66$ & $2.918,15$ & $16.833,30$ & $18.321,13$ & $16.548,89$ \\
\hline $\mathbf{1 9 9 8}$ & $15.189,55$ & $17.687,10$ & $17.660,83$ & $3.194,61$ & $3.719,88$ & $3.714,36$ & $18.384,16$ & $21.406,98$ & $21.375,19$ \\
\hline $\mathbf{1 9 9 9}$ & $15.492,11$ & $21.462,33$ & $19.983,79$ & $3.051,34$ & $4.227,24$ & $3.936,02$ & $18.543,45$ & $25.689,57$ & $23.919,81$ \\
\hline $\mathbf{2 0 0 0}$ & $31.474,20$ & $25.502,63$ & $30.662,05$ & $5.098,71$ & $4.131,34$ & $4.967,14$ & $36.572,91$ & $29.633,97$ & $35.629,19$ \\
\hline $\mathbf{2 0 0 1}$ & $36.098,20$ & $31.598,28$ & $35.797,66$ & $6.877,01$ & $6.019,74$ & $6.819,75$ & $42.975,21$ & $37.618,02$ & $42.617,41$ \\
\hline
\end{tabular}

Entretanto os valores encontrados no QUADRO 13, para os ônibus 134 e 138, referentes ao ano de 1996, devem ser ajustados, pois devido à data de aquisição dos mesmos, tais valores são oriundos da acumulação dos custos de 10 e 6 meses respectivamente, sendo necessário, para não prejudicar a aplicação do método do custo anual uniforme equivalente, que os custos sejam anuais, visto que os custos operacionais totais dos anos seguintes, representam o somatório anual dos custos, pelo fato de que os ônibus operaram durante todos os meses do ano.

Então para transformá-los em valores anuais, efetuou-se a divisão dos mesmos pelos números de meses que os ônibus operaram no ano de 1996, encontrando a média mensal dos custos do ano, que posteriormente foi multiplicada por 12 , chegando desta forma aos valores anuais de $R \$ 17.580,08$ para o ônibus 134 e $R \$$ 14.771,22 para o ônibus 138.

Desta forma, foram estabelecidos os custos totais operacionais referentes aos anos de 1996 ao 2001 de cada ônibus, que foram utilizados no método do custo anual uniforme equivalente, bastando para tal, somar os valores do QUADRO 12, com os valores do QUADRO 13, devidamente ajustado. Assim para uma melhor visualização, no QUADRO 14, serão demonstrados os custos operacionais totais que foram utilizados na aplicação do método utilizado neste trabalho.

QUADRO 14 - Custos operacionais totais (R\$).

\begin{tabular}{|c|c|c|c|}
\hline \multirow{2}{*}{ Anos } & \multicolumn{3}{|c|}{ N. $^{\circ}$ dos ônibus } \\
\cline { 2 - 4 } & $\mathbf{1 3 3}$ & $\mathbf{1 3 4}$ & $\mathbf{1 3 8}$ \\
\hline $\mathbf{1 9 9 6}$ & $16.282,67$ & $17.580,08$ & $15.129,21$ \\
\hline $\mathbf{1 9 9 7}$ & $17.138,50$ & $18.626,94$ & $16.854,09$ \\
\hline $\mathbf{1 9 9 8}$ & $18.689,96$ & $21.712,78$ & $21.680,99$ \\
\hline $\mathbf{1 9 9 9}$ & $18.864,24$ & $26.010,36$ & $24.240,60$ \\
\hline $\mathbf{2 0 0 0}$ & $36.984,14$ & $30.022,32$ & $36.040,42$ \\
\hline $\mathbf{2 0 0 1}$ & $43.349,60$ & $37.989,21$ & $42.988,60$ \\
\hline
\end{tabular}




\subsection{Taxa mínima atrativa}

Como o método do custo anual uniforme equivalente exige a aplicação de uma taxa de desconto para transformar as saídas e entradas que compõem o fluxo de caixa, em séries uniformes equivalentes, optou-se por uma taxa mínima atrativa, que corresponde à média das taxas acumuladas, no ano 2001, dos fundos de investimentos conservadores fornecidos pelo ABN AMRO Bank, visto que os mesmos não trazem riscos aos seus investidores.

Todavia, apesar da rentabilidade dos fundos estarem líquidas da taxa de administração, elas estão brutas do imposto de renda, que corresponde a $20 \%$ do rendimento do investimento. Assim, a seguir será demonstrada, no QUADRO 15, a taxa mínima atrativa antes e após o imposto de renda. Sendo que para o desenvolvimento do presente estudo, foi utilizada a taxa mínima atrativa após o imposto de renda.

QUADRO 15 - Taxa mínima atrativa após o imposto de renda.

\begin{tabular}{|l|c|c|}
\hline \multicolumn{1}{|c|}{ Fundos } & $\begin{array}{c}\text { Rentabilid } \\
\text { ade antes } \\
\text { do IR }\end{array}$ & $\begin{array}{c}\text { Rentabilidad } \\
\text { e após o IR }\end{array}$ \\
\hline REAL FAQ EXTRA DI & $13,39 \%$ & $10,71 \%$ \\
\hline REAL FAQ EXPERT DI & $13,95 \%$ & $11,16 \%$ \\
\hline REAL FAQ SUPREMO DI & $15,12 \%$ & $12,10 \%$ \\
\hline REAL FAQ CENTRUM DI & $16,34 \%$ & $13,07 \%$ \\
\hline REAL FAQ PRIORITY DI & $16,91 \%$ & $13,53 \%$ \\
\hline REAL FAQ FORÇAS DI & $15,68 \%$ & $12,54 \%$ \\
\hline REAL FAQ DOUTOR DI & $16,34 \%$ & $13,07 \%$ \\
\hline REAL FAQ SAUDE DI & $16,92 \%$ & $13,54 \%$ \\
\hline REAL FAQ PEQ. EMPRESA DI & $15,16 \%$ & $12,13 \%$ \\
\hline REAL FAQ EXTRA MIX & $12,84 \%$ & $10,27 \%$ \\
\hline REAL FAQ EXPERT MIX & $13,41 \%$ & $10,73 \%$ \\
\hline REAL FAQ SUPREMO MIX & $15,10 \%$ & $12,08 \%$ \\
\hline REAL FAQ CENTRUM MIX & $16,35 \%$ & $13,08 \%$ \\
\hline REAL FIF MIX & $16,93 \%$ & $13,54 \%$ \\
\hline REALPREV FIX & $14,23 \%$ & $11,38 \%$ \\
\hline FIF REALPREV RF & $15,84 \%$ & $12,67 \%$ \\
\hline Taxa mínima atrativa & $\mathbf{1 5 , 2 8 \%}$ & $\mathbf{1 2 , 2 3 \%}$ \\
\hline
\end{tabular}




\subsection{Cálculo da vida útil econômica}

Para calcular a vida útil econômica dos ônibus 133, 134 e 138, foi utilizado o método do custo anual uniforme equivalente, como já foi dito anteriormente, operacionalizado através de uma ferramenta gerencial desenvolvida em planilhas eletrônicas Excel ${ }^{\circledR}$.

Foram desenvolvidas três planilhas, sendo que a primeira é uma planilha de entrada de dados, onde se deve preencher todos os campos com as devidas informações. Já na segunda planilha, onde são calculados os custos anuais uniformes equivalentes (CAUE), não precisa ser preenchido nenhum campo, visto tal planilha estar totalmente integrada com a primeira. Por fim, na última planilha é demonstrado um gráfico, onde se pode visualizar a idade de vida útil econômica do bem em análise, que é o ponto onde o valor do custo anual uniforme equivalente é menor.

Assim, alimentando as planilhas com as informações sobre os ônibus 133, 134 e 138 , obteve-se os valores dos custos anuais equivalentes dos referidos bens para os anos de 1996 a 2001, sendo que tais valores estão demonstrados nos quadros e gráficos a seguir relacionados.

FIGURA 3 - Modelo de planilha para aplicação prática do método do custo anual

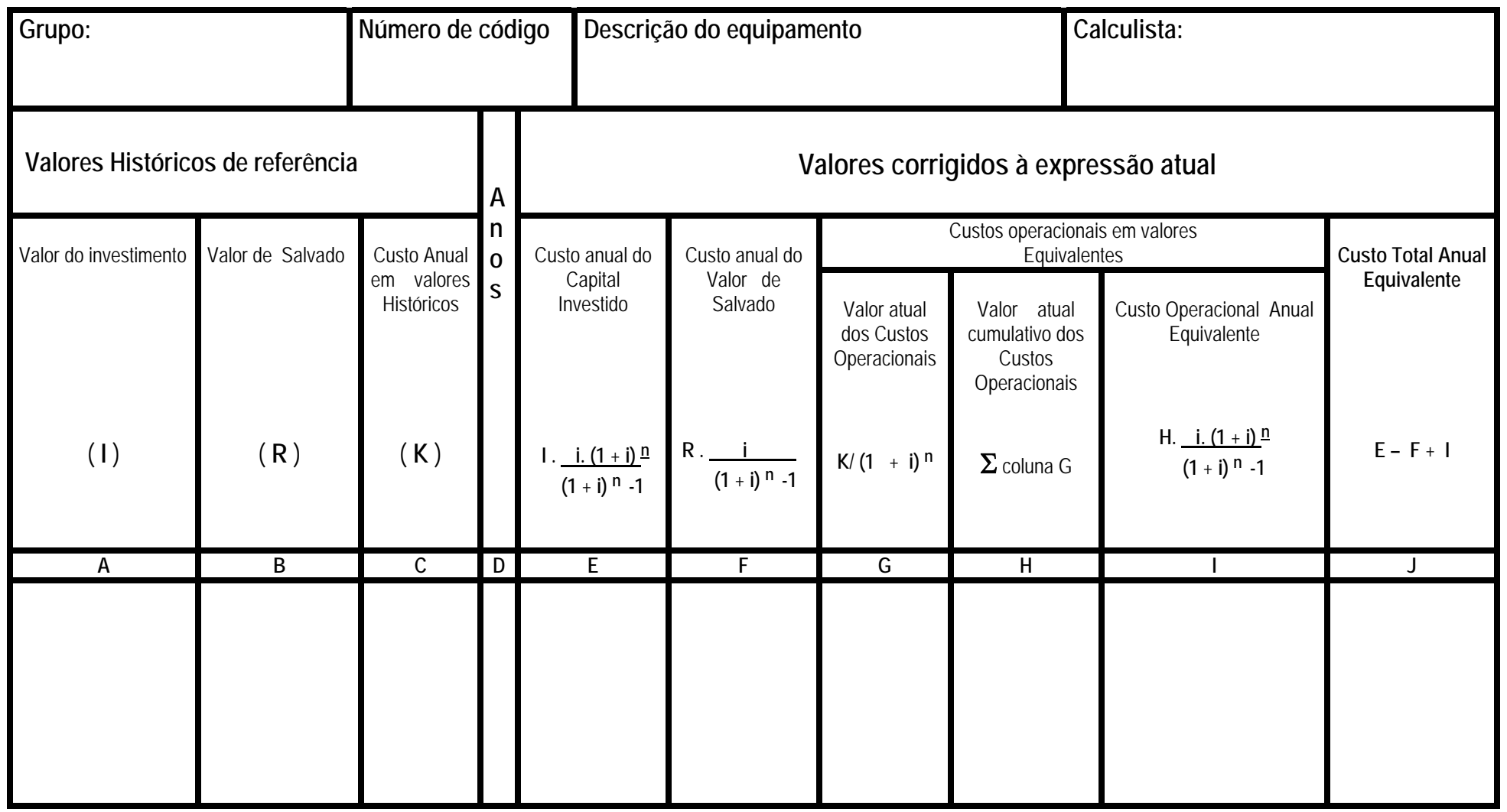


uniforme equivalente

QUADRO 16 - Custo anual uniforme equivalente do ônibus 133

\begin{tabular}{|c|c|c|c|c|c|c|c|c|c|c|c|c|}
\hline 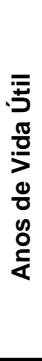 & 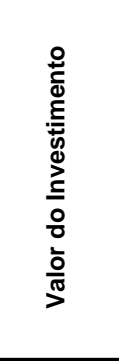 & 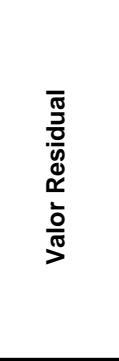 & 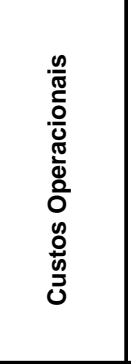 & $(1+i)$ & 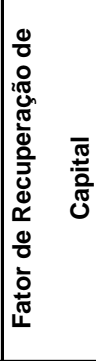 & 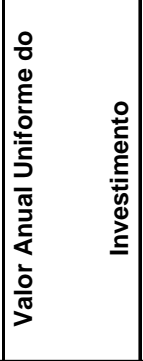 & 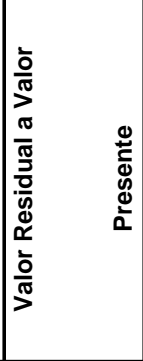 & 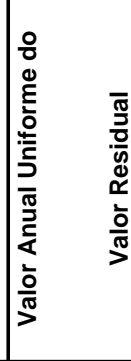 & 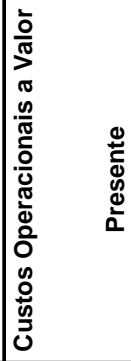 & 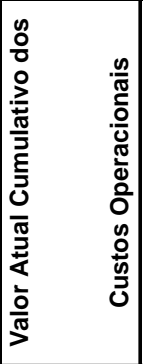 & 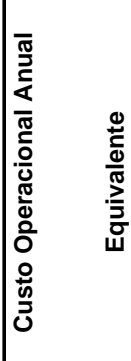 & 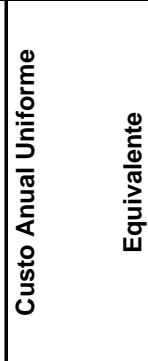 \\
\hline 1 & $69.546,49$ & 878 & 2,67 & 1223 & 1223 & $.052,03$ & $9.842,98$ & $55.938,78$ & $14.508,30$ & $14.508,30$ & $16.282,67$ & $38.395,92$ \\
\hline 2 & & 10 & & 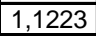 & 59 & & & & 13 & & & $\overline{05}$ \\
\hline 3 & & 34.670 & $3.689,96$ & 1,1223 & 0,4180 & $29.070,12$ & $24.526,62$ & $10.252,02$ & $13.221,52$ & 36,59 & 78,51 & 96,61 \\
\hline 4 & & 6.80 & $3.864,24$ & $\angle 23$ &, 3308 & 3,11 & 16.8 & 9,46 & 11. & 7,18 & 9,18 & \\
\hline 5 & & & & & & & 12.2 & & & & & \\
\hline 6 & & $17.707,96$ & $43.349,60$ & \begin{tabular}{|l|}
1,1223 \\
\end{tabular} & 2448 & $17.025,83$ & $8.861,65$ & $2.169,44$ & $21.693,58$ & $95.692,40$ & $23.426,66$ & $38.283,05$ \\
\hline 7 & & 0 & 0 & 1 & & & & 0,00 & $\underline{0}$ & & & \\
\hline 8 & & & 00 & & & & & & 0,00 & & & \\
\hline 9 & & 0,00 & 0,00 & \begin{tabular}{|l|}
1,1223 \\
\end{tabular} & 0,1893 & $13.166,73$ & 0,00 & 0,00 & 0,00 & $95.692,40$ & \begin{tabular}{|l}
$18.116,75$ \\
\end{tabular} & $31.283,48$ \\
\hline 4 & & 0,00 & 0,00 & 1,1223 & 0,1787 & $12.424,74$ & 0,00 & 0,00 & 0,00 & $95.692,40$ & $17.095,80$ & $29.520,54$ \\
\hline
\end{tabular}

FIGURA 4 - Gráfico do custo anual uniforme equivalente do ônibus 133

\section{Custo Anual Uniforme Equivalente}

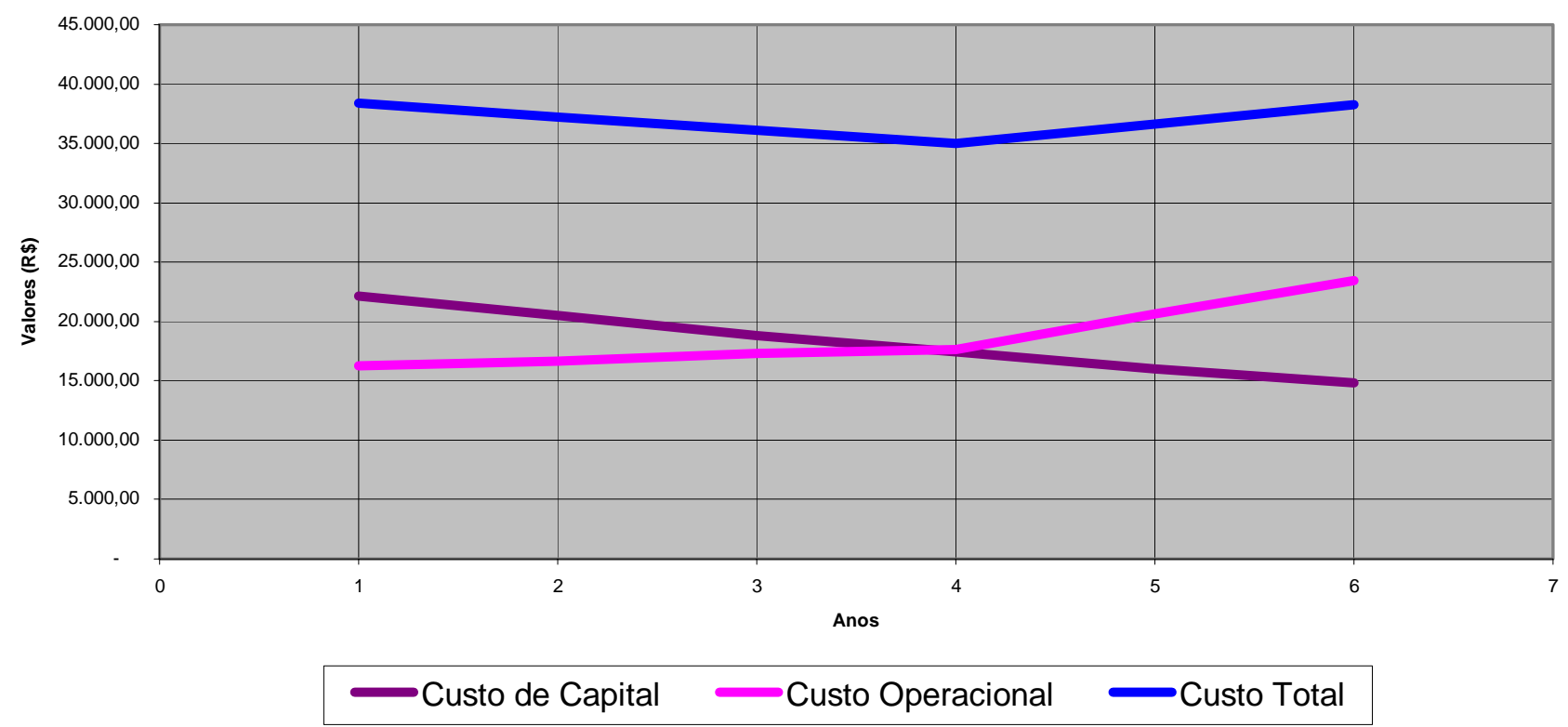


QUADRO 17 - Custo anual uniforme equivalente do ônibus 134

\begin{tabular}{|c|c|c|c|c|c|c|c|c|c|c|c|c|}
\hline 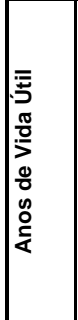 & 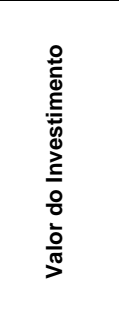 & 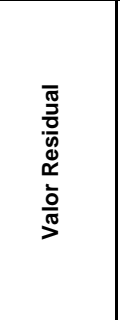 & 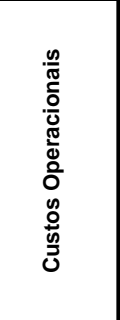 & $(1+\mathrm{i})$ & 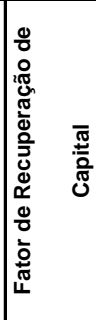 & 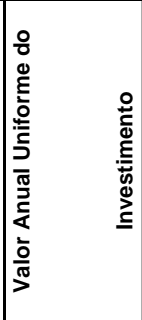 & 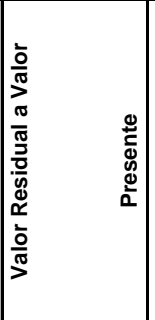 & 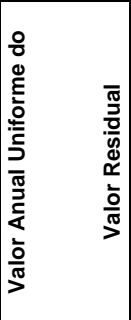 & 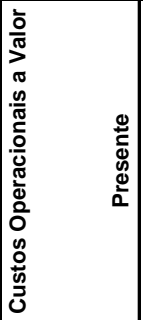 & 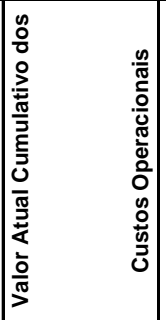 & 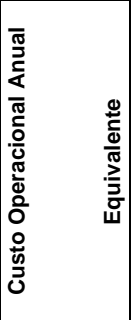 & 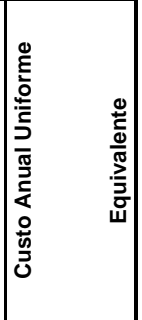 \\
\hline & $\begin{array}{l}71.794,76 \\
\end{array}$ & $58.332,12$ & $\begin{array}{l}17.580,08 \\
\end{array}$ & 1,1223 & 1,1223 & $80.575,26$ & $51.975,51$ & $58.332,12$ & $15.664,33$ & $15.664,33$ & $17.580,08$ & $39.823,22$ \\
\hline 2 & & $\begin{array}{l}46.051,90 \\
\end{array}$ & $\begin{array}{l}18.626,94 \\
\end{array}$ & 1,1223 & 0,5935 & $42.609,25$ & $\begin{array}{l}36.561,97 \\
\end{array}$ & $21.699,05$ & $14.788,48$ & 2,81 & $18.073,35$ & 983,54 \\
\hline & & $\begin{array}{l}36.082,63 \\
\end{array}$ & \begin{tabular}{|l|}
$21.712,78$ \\
\end{tabular} & 1,1223 & 0,4180 & $30.009,89$ & \begin{tabular}{|l|}
$25.525,33$ \\
\end{tabular} & $10.669,47$ & $15.359,91$ & $45.812,72$ & $19.149,51$ & $38.489,93$ \\
\hline 4 & & $\begin{array}{l}27.874,90 \\
\end{array}$ & $26.010,36$ & 1,1223 & 0,3308 & $23.751,91$ & 17.5 & $5.812,77$ & 16.39 & & $20.580,21$ & $38.519,34$ \\
\hline 5 & & $22.213,99$ & & 1,1223 & 0,2790 & $20.030,17$ & $\begin{array}{l}12.476,18 \\
\end{array}$ & $3.480,76$ & 16.8 & 9,31 & $22.059,71$ & $38.609,1$ \\
\hline 6 & & $18.081,66$ & \begin{tabular}{|l|}
$37.989,21$ \\
\end{tabular} & 1,1223 & 0,2448 & $17.576,23$ & $9.048,67$ & $2.215,22$ & $19.011,07$ & \begin{tabular}{|l|}
$98.080,38$ \\
\end{tabular} & $24.011,27$ & $39.372,2 \varepsilon$ \\
\hline & & 0,00 & 0,00 & 1,1223 & 0,2207 & $15.846,41$ & 0 & 0,00 & 000 & 0,38 & $21.648,12$ & 37.49 \\
\hline 8 & & 0,00 & 0,00 & 1,12 & 0,2029 & $14.568,82$ & 0, & 0,00 & 0,00 & $98.080,38$ & $19.902,78$ & 34.471, \\
\hline 9 & & 0,00 & 0,00 & 1,1223 & 0,1893 & $13.592,38$ & 0,00 & 0,00 & 0,00 & \begin{tabular}{|l|}
$98.080,38$ \\
\end{tabular} & $18.568,84$ & $32.161,22$ \\
\hline 10 & & 0,00 & 0,00 & 1,1223 & 0,1787 & $12.826,40$ & 0,00 & 0,00 & 0,00 & $98.080,38$ & $17.522,42$ & $30.348,82$ \\
\hline
\end{tabular}

FIGURA 5 - Gráfico do custo anual uniforme equivalente do ônibus 134

Custo Anual Uniforme Equivalente

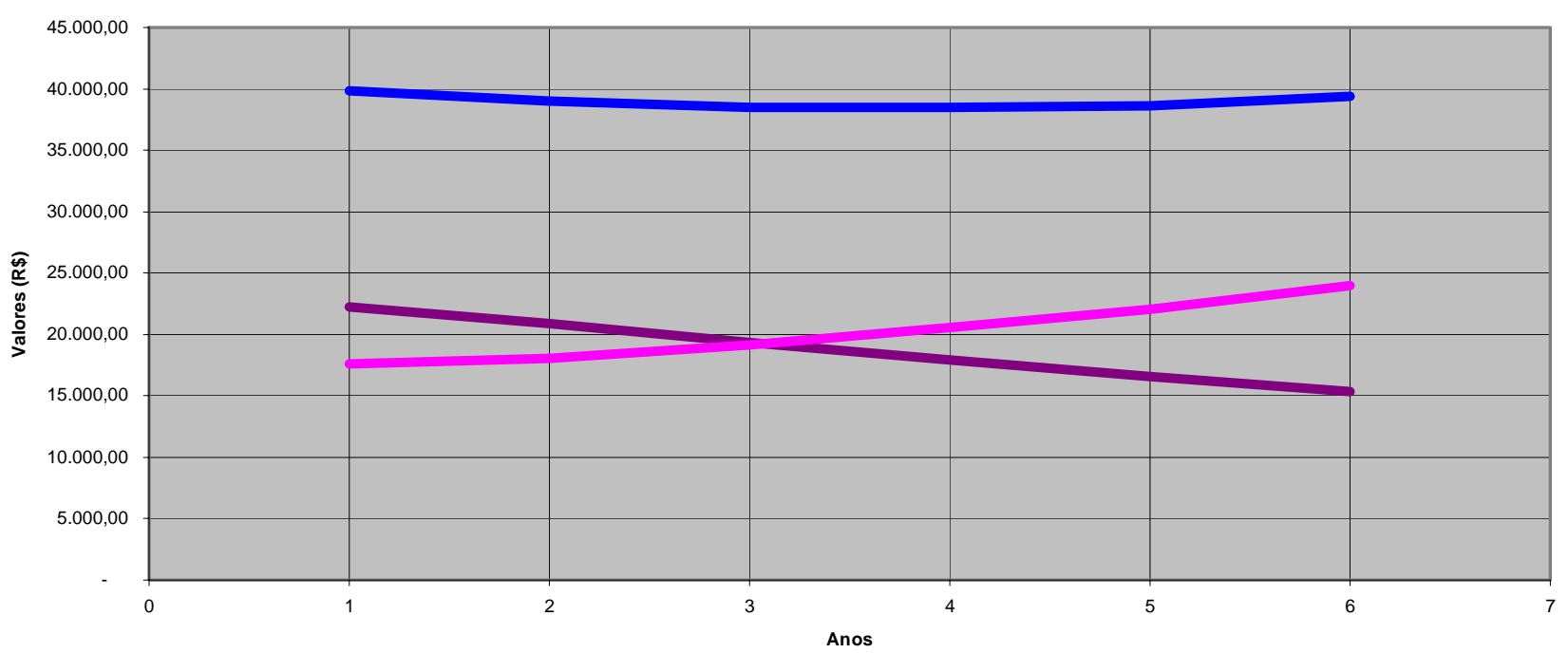

$\longrightarrow$ Custo de Capital $\longrightarrow$ Custo Operacional $\rightleftharpoons$ Custo Total 
QUADRO 18 - Custo anual uniforme equivalente do ônibus 138

\begin{tabular}{|c|c|c|c|c|c|c|c|c|c|c|c|c|}
\hline 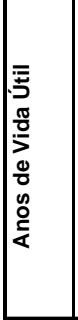 & 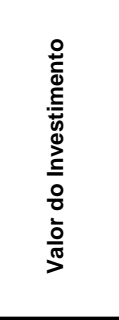 & 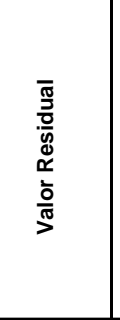 & 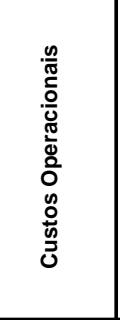 & $(1+\mathrm{i})$ & 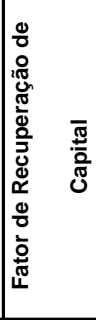 & 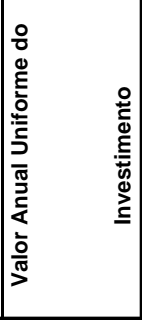 & 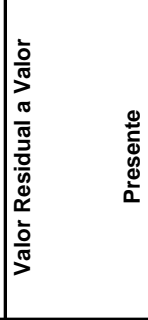 & 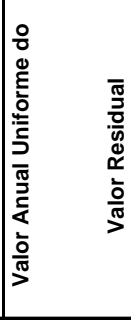 & 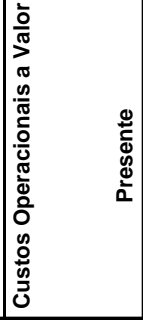 & 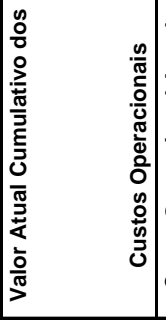 & 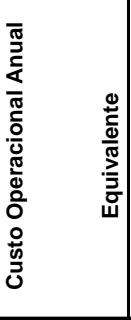 & 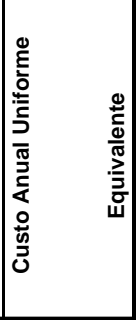 \\
\hline & $71.315,29$ & \begin{tabular}{|l|}
$57.981,39$ \\
\end{tabular} & $\begin{array}{l}15.129,21 \\
\end{array}$ & 1,1223 & 1,1223 & $80.037,15$ & $51.663,00$ & $57.981,39$ & $13.480,54$ & $13.480,54$ & $15.129,21$ & $37.184,97$ \\
\hline & & & $\begin{array}{l}16.854,09 \\
\end{array}$ & 1,1223 & 0,5935 & & & & $13.380,96$ & \begin{tabular}{l|l}
$26.861,50$ \\
\end{tabular} & $15.941,95$ & $36.467,54$ \\
\hline 3 & & $36.329,39$ & $21.680,99$ & 1,1223 & 0,4180 & $29.809,47$ & $25.699,89$ & $10.742,44$ & $15.337,42$ & $42.198,92$ & $17.638,96$ & $36.705,99$ \\
\hline 4 & & \begin{tabular}{l|l}
$28.144,30$ \\
\end{tabular} & $24.240,60$ & 1,1223 & 0,3308 & $23.593,28$ & $17.740,04$ & $5.868,95$ & $15.279,44$ & \begin{tabular}{|l|}
$57.478,36$ \\
\end{tabular} & $19.015,60$ & $36.739,94$ \\
\hline 5 & & $21.932,25$ & $\begin{array}{l}36.040,42 \\
\end{array}$ & 1,1223 & 0,2790 & $19.896,40$ & $12.317,95$ & $3.436,61$ & $20.241,61$ & $\begin{array}{l}77.719,97 \\
\end{array}$ & $21.683,26$ & $38.143,05$ \\
\hline 6 & & $17.818,28$ & $42.988,60$ & 1,1223 & 0,2448 & $17.458,85$ & $8.916,86$ & $2.182,96$ & $21.512,93$ & $99.232,90$ & $24.293,42$ & $39.569,32$ \\
\hline 7 & & 0,00 & 0,00 & 1,1223 & 0,2207 & $15.740,58$ & 0,00 & 0,00 & 0,00 & \begin{tabular}{|l|}
$99.232,90$ \\
\end{tabular} & $21.902,51$ & $37.643,09$ \\
\hline 8 & & 0,0 & 0,00 & 1,1223 & 0,2029 & $14.471,53$ & 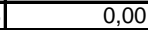 & 0,00 & 0,00 & $99.232,90$ & $20.136,66$ & \\
\hline 9| & & 0,00 & 0,00 & 1,1223 & 0,1893 & $13.501,61$ & 0,00 & 0,00 & 0,00 & \begin{tabular}{|c|}
$99.232,90$ \\
\end{tabular} & $18.787,04$ & $32.288,65$ \\
\hline 10 & & 0,00 & 0,00 & 1,1223 & \begin{tabular}{|l|}
0,1787 \\
\end{tabular} & $12.740,74$ & 0,00 & 0,00 & 0,00 & \begin{tabular}{|c|}
$99.232,90$ \\
\end{tabular} & $17.728,32$ & $30.469,06$ \\
\hline
\end{tabular}

FIGURA 6 - Gráfico do custo anual uniforme equivalente do ônibus 138

Custo Anual Uniforme Equivalente

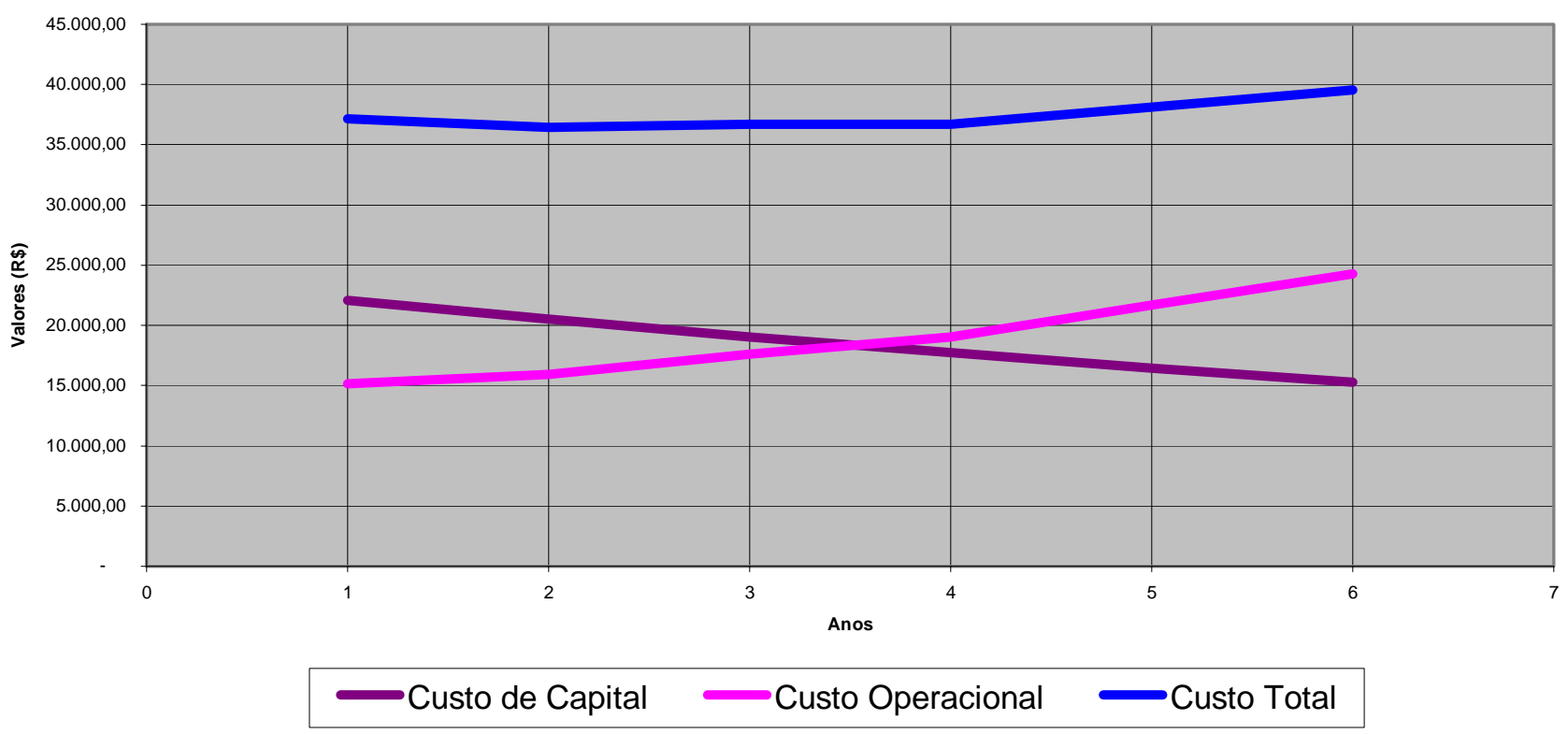


QUADRO 19 - Custos anuais uniformes equivalentes.

\begin{tabular}{|c|c|c|c|}
\hline \multirow{2}{*}{ Anos } & \multicolumn{3}{|c|}{ N. $^{\circ}$ dos ônibus } \\
\cline { 2 - 4 } & $\mathbf{1 3 3}$ & $\mathbf{1 3 4}$ & $\mathbf{1 3 8}$ \\
\hline $\mathbf{1 9 9 6}$ & $38.395,92$ & $39.823,22$ & $37.184,97$ \\
\hline $\mathbf{1 9 9 7}$ & $37.200,56$ & $38.983,54$ & $36.467,54$ \\
\hline $\mathbf{1 9 9 8}$ & $36.096,61$ & $38.489,93$ & $36.705,99$ \\
\hline $\mathbf{1 9 9 9}$ & $35.027,83$ & $38.519,34$ & $36.739,94$ \\
\hline $\mathbf{2 0 0 0}$ & $36.640,86$ & $38.609,13$ & $38.143,05$ \\
\hline $\mathbf{2 0 0 1}$ & $38.283,05$ & $39.372,28$ & $39.569,32$ \\
\hline
\end{tabular}

\section{CONCLUSÕES}

Através do desenvolvimento do presente estudo, pode-se estabelecer que os ônibus 133, 134 e 138, que foram objetos de análise deste trabalho, possuem, respectivamente, 4, 3 e 2 anos de vida útil econômica. Assim, conclui-se que, de acordo com o método do custo anual uniforme equivalente (CAUE), as substituições dos mesmos poderiam ter ocorrido, respectivamente, no final dos anos de 1999, 1998 e 1997.

Entretanto, observando-se os valores encontrados para os custos anuais uniformes equivalentes do ônibus 134, nota-se que, o valor do "CAUE" mínimo encontrado no terceiro ano de utilização do ativo permanente, é semelhante aos valores do quarto e quinto ano. Já o valor mínimo do "CAUE" referente ao ônibus 138, que ocorreu no segundo ano de operação do mesmo, é bem semelhante aos calculados no terceiro e quarto ano.

Assim, analisando-se o conjunto dos valores dos custos anuais uniformes equivalentes encontrados para os ônibus 134 e 138 nota-se que a vida útil econômica do primeiro está situada entre o terceiro e quinto ano de utilização do mesmo. Já a vida útil econômica do segundo, está entre o segundo e quarto ano.

Então, pode-se dizer que para os ônibus 134 e 138, não existe um único período de vida útil econômica, mas um intervalo ideal de substituição, ou seja, existe uma região na vida de cada um, em que os mesmos devem ser substituídos para gerarem a melhor lucratividade à empresa. 
Após os resultados obtidos, conclui-se que o método do custo anual uniforme equivalente pode ser perfeitamente aplicado às empresas do setor de transporte coletivo como ferramenta de avaliação para a substituição de suas frotas. No entanto, as empresas necessitam de uma contabilidade muito bem estruturada, que possua informações confiáveis e atualizadas, as quais facilitem a coleta de dados necessários para a aplicação prática do método em estudo, tais como: informações para a determinação do custo de capital ponderado da empresa, valores residuais dos ônibus ao final de cada ano e os custos da mão-de-obra da manutenção.

Finalmente, recomenda-se que o cálculo da vida útil econômica da frota não seja realizada em conjunto, mas individualmente para cada ônibus, pois o valor dos custos operacionais, normalmente, variam de um ônibus para outro devido a fatores como: quilometragem percorrida, condições das linhas em que trafegam, maneira como são conduzidos, entre outros.

Salienta-se que o cálculo da vida útil econômica, utilizando-se o método do custo anual uniforme equivalente, indica o período ótimo de substituição dos ônibus, o que é muito importante para a empresa não se desfazer de bens que contribuem positivamente na formação de lucros ou manter em funcionamento bens que the tragam prejuízos.

Através deste trabalho não pretendeu-se encerrar os estudos do tema em questão, até porque o assunto é vasto, mas sim, contribuir à ciência contábil com um estudo que poderá servir de base a outros que poderão ser desenvolvidos posteriormente.

\section{BIBLIOGRAFIA}

BACKER, Morton, JACOBSEN, Lyle E. Contabilidade de Custos: uma abordagem gerencial. Tradução de José Carlos Marion e Mussoline Orru. 2. ed. São Paulo: McGraw-Hill, 1984.

Contabilidade de Custos: um enfoque de administração de empresas. Tradução de Pierre Louis Laporte. 1. ed. v. 1. São Paulo: McGraw-Hill, 1977.

- Contabilidade de Custos: um enfoque de administração de empresas. Tradução de Pierre Louis Laporte. 1. ed. v. 2. São Paulo: McGraw-Hill, 1977.

BRAGA, Roberto. Fundamentos e técnicas de administração financeira. 1. ed. São Paulo: Atlas, 1995.

CALDERELLI, Antônio. Enciclopédia contábil brasileira. 1. ed. v. 1. São Paulo: Formar, 1975.

Enciclopédia contábil brasileira. 1. ed. v. 2. São Paulo: Formar, 1975. 
CASAROTTO FILHO, Nelson, KOPITTKE, Bruno Hartmut. Análise de Investimentos. 9. ed. São Paulo: Atlas, 2000.

DE ROCCHI, Carlos Antonio. Sobre as políticas de investimentos em ativos permanentes ( $1^{\text {a }}$ Parte). Revista do conselho regional de contabilidade do Rio Grande do Sul, Porto Alegre, n. 48, 1987, p. 10-31.

Aplicação do método do prazo de recuperação no gerenciamento dos ativos depreciáveis. Revista do conselho regional de contabilidade do Rio Grande do Sul, Porto Alegre, n. 94, 1998, p. 15-21.

Método de Orenstein e suas aplicações práticas. Revista do conselho regional de contabilidade do Rio Grande do Sul, Porto Alegre, n. 91, 1997, p. 30-35.

- - O método de Clapham: embasamento teórico e sugestões para sua aplicação prática. Contabilidade Vista \& Revisada, v. 8, n. 2, Belo Horizonte, 1997, p. 49-55.

DORNELLES, Joaquim Luiz Rodrigues. Avaliação de investimentos em ativo imobilizado: um estudo focalizado em empresas brasileiras do setor de transporte rodoviário de cargas. Universidade de São Paulo, 2001.

EHRLICH, Pierre Jacques. Avaliação e seleção de projetos de investimento: critérios quantitativos. 1. ed. São Paulo: Atlas, 1977.

GITMAN, Lawrence J.. Princípios de administração financeira. Tradução de Jean Jacques Salim e João Carlos Douat. 7. ed. São Paulo: Harbra, 1997.

HORNGREN, Charles T.. Contabilidade de Custos: um enfoque administrativo. Tradução de Danilo A. Nogueira. 1. ed. v. 1. São Paulo: Atlas, 1978.

Contabilidade de Custos: um enfoque administrativo. Tradução de Danilo A. Nogueira. 1. ed. v. 2. São Paulo: Atlas, 1978.

IUDÍCIBUS, Sérgio, MARTINS, Eliseu, GELBCKE, Ernesto. Manual de Contabilidade das Sociedades por Ações: aplicável também às demais sociedades. 4. ed. São Paulo: Atlas, 1995.

MAYER, Raymond R.. Análise financeira de alternativas de investimento. Tradução de Antonio Zoratto Sanvicente. 1. ed. São Paulo: Atlas, 1972.

ORNSTEIN, Rudolf. O retorno sobre o investimento como critério decisório. Revista do conselho regional de contabilidade do Rio Grande do Sul, Porto Alegre, $\mathrm{n}$. 4, 1973, p. 13-16.

PUCCINI, Abelardo de Lima, MARQUES, José Luiz de Moura, HESS, Geraldo, PAES, Luiz Carlos Medeiros da Rocha. Engenharia econômica e análise de investimentos. 1. ed. Rio de Janeiro: Fórum, 1969.

SANVICENTE, Antonio Zoratto. Administração financeira. 1. ed. São Paulo: Atlas, 1977.

SOUZA, Alceu, CLEMENTE, Ademir. Decisões financeiras e análise de investimentos: fundamentos, técnicas e aplicações. 2. ed. São Paulo: Atlas, 1997.

VELHO, Paulo Ricardo Aquino de Campos. Renovação de frota em uma empresa de transporte coletivo intermunicipal de passageiros: um estudo de caso. Universidade Federal de Santa Maria, 1997. 